\title{
Freud, Brentano e a Concomitância Dependente
}

\author{
Thiago Marcellus de Souza Cataldo Maria ${ }^{1}$ \\ Monah Winograd \\ Pontifícia Universidade Católica do Rio de Janeiro
}

\begin{abstract}
RESUMO - No campo das interações entre o corporal e o anímico, a noção de concomitância dependente é um dos principais pilares capazes de sustentar a soberania não apenas da psicanálise, mas da psicologia de um modo geral. Formulada por Freud em seu manuscrito sobre as afasias, de 1891, ela é comumente associada à contribuição do neurologista britânico John Hughlings Jackson. Não contrariando este julgamento, o presente trabalho visa examiná-la ainda à luz dos ensinamentos do filósofo Franz Brentano, professor de Freud durante sua graduação em medicina. Com isso, pretende-se elevar a noção de concomitância para além da condição de imperativo metodológico.
\end{abstract}

Palavras-chave: Freud, Brentano, concomitante, hilemorfismo, dualismo

\section{Freud, Brentano and Dependent Concomitance}

\begin{abstract}
In the field of interactions between the physical and the mental, the notion of dependent concomitance is one of the main pillars able to sustain not only Psychoanalysis' sovereignty, but also that of Psychology as a whole. Formulated by Freud in his manuscript from 1891 regarding aphasias, it is usually associated with the contribution of the British neurologist John Hughlings Jackson. Not contradicting this judgement, the present work aims to examine this notion further in the light of the teachings of the philosopher Franz Brentano, Freud's professor during his graduation in Medicine. In so doing, we intend to elevate the notion of concomitance beyond its condition of methodological imperative.
\end{abstract}

Keywords: Freud, Brentano, concomitant, hylomorphism, dualism

A aproximação entre as obras de Franz Brentano (18381917) e Sigmund Freud (1856-1939) está longe de remeter o estudioso a uma trilha frequentemente visitada. CataldoMaria e Winograd (2013) sublinham a escassez bibliográfica encontrada sempre que a pesquisa recai sobre o diálogo entre o metapsicólogo e o filósofo neoescolástico. Porém, quando se estipula o recorte do estudo para que incida precisamente sobre a noção de concomitância dependente tal como encontrada em Freud, a escassez parece regredir para uma inexistência pura e simples. Não encontramos uma tentativa sequer de aproximar Freud e Brentano por meio da exploração desta noção tão cara para o surgimento da psicanálise como "uma disciplina independente, com sua própria linguagem, conceitos e construções que não eram físico-químicos, tampouco neurofisiológicos" (Edelheit, 1976, p.24).

Os contornos do que só surgiria explicitamente como concomitância dependente com a publicação de seu primeiro livro, Interpretação das Afasias (Freud, 1891/1977), já se faziam notar desde 1888: referimo-nos ao artigo Cérebro, publicado no primeiro volume do Handwörterbuch der gesamten medizin. Maiores informações podem ser encontradas em Winograd (2013), havendo ainda a tradução inglesa do artigo, disponível em Solms e Saling (1990). A consulta à célebre monografia de 1891 não nos permite dúvida alguma quanto às origens da noção de concomitância:

1 Endereço para correspondência: Pontifícia Universidade Católica do Rio de Janeiro, Departamento de Psicologia, Rua Marquês de São Vicente 225, sala 201, Ed. Cardeal Leme, Gávea, Rio de Janeiro, RJ, Brasil. CEP: 22.453-900. E-mail: thiago.marcellus.11@gmail.com trata-se de uma dívida, declarada por Freud em meio a caloroso elogio, para com um colega britânico: o neurologista John Hughlings Jackson (1835-1911). Diga-se de passagem que Freud foi um dos poucos na Europa continental a conferir "qualquer tipo de atenção" às ideias de Jackson (Eling, 1994, p. 142). Sendo assim, de que nos valeria articular uma herança explicitamente "jacksoniana" na obra de Freud, com as ideias de Franz Brentano? Estaríamos insinuando, sobre este ponto, alguma influência não declarada do filósofo? Não exatamente, ou, dito de outra forma, não necessariamente diretamente.

Não temos a pretensão de desvendar o que se passava na mente de Freud enquanto escrevia: suas motivações mais íntimas ou a trilha imaginativa percorrida ao longo da edificação de seu corpo teórico são evidentemente inacessíveis. Na ausência de uma afirmação clara do autor, capaz de dar cabo de quaisquer dúvidas (como é o caso com relação a Jackson e a noção de concomitância), não ditaremos influências ocultas. Não obstante, partindo do que sabemos da relação entre Freud e Brentano, é possível afirmar que nenhuma das considerações que faremos no presente artigo teria sido estrangeira ao metapsicólogo.

Freud foi aluno de Brentano na Universidade de Viena durante quatro semestres, a partir do segundo ano do curso de medicina, durante o intervalo entre o inverno de 1874-75 e o inverno de 1876-77 (Merlan, 1949). Digna de nota é a constatação de que a participação nas preleções do filósofo sempre foi fruto da livre escolha de Freud: já não mais havia obrigatoriedade de ingresso nos cursos de filosofia para os futuros médicos desde 1873 e, ao longo 
de todo o curso de Medicina, Freud jamais se inscreveu em nenhuma disciplina não obrigatória, além das proferidas por Brentano (Cohen, 2002). Ainda conforme a pesquisa feita por Philip Merlan (1949), e respaldados pela valiosa correspondência entre Freud e seu amigo Eduard Silberstein (Freud, 1871-1881/1995), sabemos que, entre os temas estudados, encontravam-se: o utilitarismo de Stuart Mill - autor que anos mais tarde teria um dos volumes de suas obras completas traduzido pelo próprio Freud, por indicação de Brentano (Molnar, 2002) -, lógica, Feuerbach e questões selecionadas da metafísica de Aristóteles (Merlan, 1949). O grande mestre de Estagira nos será de especial interesse no presente trabalho.

Talvez não seja exagerado afirmar que, tão ou mais importantes do que os tópicos tratados em sala de aula, fossem as diretrizes apontadas para o bom ingresso na filosofia. Quais eram as leituras fundamentais? Na vasta lista de nomes familiares aos ouvidos dos frequentadores dos seminários de filosofia, como separar o joio do trigo? Quais eram os gigantes ocidentais dignos de atenção cuidadosa e quais aqueles que não passavam (de acordo com Brentano) de embusteiros sofistas? É Freud quem, franca e divertidamente, responde:

Deveríamos começar com Descartes, lendo dele tudo, porque é dele que emana um novo impulso para a filosofia. De seus sucessores, Geulincx, Malebranche, Spinoza, nenhum merece ser lido. Vinculam-se todos à faceta errada da filosofia de Descartes, a sua completa separação da alma e do corpo. Spinoza se movimenta em meio a puros sofismas; é ele o em que menos se pode confiar. Locke e Leibniz, ao contrário, não podem ser evitados; o primeiro é um pensador extremamente engenhoso, o último chega a ser deficiente somente porque se dispersa em demasia. A ambos se segue a filosofia popular, mas conhecer alguma coisa deles teria apenas importância cultural e histórica, não filosófica. [...] Por outro lado, do período do ceticismo não podem ser contornados nem Hume nem Kant, sendo Hume, dentre todos os filósofos, o que pensou com maior exatidão e que escreveu com a maior perfeição. Kant, porém, não merece, de forma alguma, a reputação que se lhe concede, está cheio de sofismas, é um pedante insuportável e se alegra como uma criança quando pode dividir alguma coisa em três ou quatro partes, de onde provém as invenções e ficções de seus esquemas. (Freud, 1871-1881/1995, pp. 122-123, o grifo é nosso)

A passagem acima foi extraída da carta a Silberstein datada de 15 de março de 1875 , e muito provavelmente tratase do primeiro registro histórico de um tangenciamento por parte do futuro inventor da psicanálise acerca do problema corpo-psiquismo. É verdade que a passagem diz respeito ao relato de Freud quanto às instruções de Brentano. Exigese cautela: não se deve especular o que Freud pensava a respeito do assunto, ao menos não na ocasião. No entanto, quão significativa é a constatação de que, já aos 18 anos de idade, Freud ia tomando posse dos instrumentos capazes de assegurar-lhe uma visão apta a perceber toda "a grande agudeza" (Freud, 1891/1977, p. 31) de Hughlings Jackson no seu tratamento das relações entre o físico e o psíquico.

Agora, já é possível circunscrever melhor nosso argumento central: no decorrer dos dois anos passados na companhia de Brentano - não apenas como mais um dentre tantos alunos, já que o próprio Freud (1871-1881/1995) qualificou a relação como "estreita" (p. 116) e "íntima" (p. 121) - o jovem estudante teve a oportunidade, sobretudo por meio da fiel exposição a uma vasta tradição filosófica, estendendo-se através dos escolásticos da Idade Média até Aristóteles (Beuchot, 1998), de adquirir munição intelectual cuja consonância para com algumas inovações trazidas à neurologia de sua época salta aos olhos. Assim, acreditamos encontrar uma espécie de complementaridade negligenciada entre as heranças de Franz Brentano e John Hughlings Jackson.

Guiados por elementos conceituais caros a uma cosmologia antiga, sobretudo as noções de Forma e Matéria presentes na doutrina hilemórfica lançada por Aristóteles e desenvolvida por S. Tomás de Aquino, é possível, de início, situar conceitualmente, em seu devido lugar, a intencionalidade revivificada por Brentano. Apontada por Beuchot (1998) e Barclay (1964) como importante herança de Brentano a Freud, e utilizada por Garcia-Roza (2004) para ilustrar a concordância presente entre professor e aluno quanto a não redução do psíquico ao fisiológico, a doutrina em questão, compreendida isoladamente de seu contexto originário (Aristóteles e seus comentadores escolásticos), pode facilmente render conclusões absurdas. Por exemplo, a de um psiquismo substancialmente distinto do fisiológico, uma vez que permite a distinção entre fenômenos físicos e estritamente mentais. Mais especificamente no que tange à relação entre o psíquico e o fisiológico, veremos que Brentano dedicou uma parte significativa de sua Psicologia do ponto de vista empírico (1874/1995) à análise cuidadosa e subsequente refutação dos principais argumentos em prol da redução do primeiro ao segundo. Ao tratar dos métodos de investigação adequados para o que ele denomina "leis fundamentais da psicologia" (pp. 33-48), o autor chega mesmo a utilizar, em mais de uma ocasião, o termo concomitância com o intuito de ilustrar a natureza da relação.

Em segundo lugar, é possível também conferir à noção de concomitância dependente o respaldo conceitual capaz de assegurar-lhe a amplitude devida. A doutrina hilemórfica endossada por Brentano, permite ir além da mera afirmação de uma correlação que não seja meramente a de uma causalidade mecânica entre estados nervosos e estados mentais, tal como afirmado pela doutrina do paralelismo psicofísico (FerraterMora, 2000, pp. 2204-2205). Preserva-se, deste modo, o que por enquanto chamaremos de sutil distinção entre ser não mais que e ser por meio de ou em virtude de. Enfatizase, por assim dizer, a dependência da concomitância. Por fim, uma vez aceita a tese de complementaridade presente nas heranças oriundas do filósofo e do neurologista, a noção de concomitância firma-se no terreno da ontologia. A contribuição do hilemorfismo à noção de concomitância dependente implica na sua não limitação como mero imperativo metodológico.

Da articulação entre a noção de concomitância e os ensinamentos do filósofo, portanto, não demonstraremos evidências de uma influência direta. Aliás, falar em influência direta quando o assunto é o encontro entre Freud e Brentano já é delicado mesmo quando o discurso se limita aos pontos de interlocução mais conhecidos, a saber: a doutrina da intencionalidade e o conceito de representação, sobretudo 
este último. Primeiramente, ao longo de toda a obra freudiana encontramos apenas uma única menção a Brentano: uma nota de rodapé em $O$ chiste e sua relação com o inconsciente. No mais, a carência de um consenso entre os comentadores oscila entre (a) a defesa de uma influência especificamente direcionada ao conceito de representação (Garcia-Roza, 2004; Cataldo-Maria \& Winograd, 2013); (b) a articulação entre a noção de investimento (Besetzung, a catexia das traduções mais antigas) e a doutrina da intencionalidade (Barclay, 1964); (c) um reflexo dos ensinamentos de Brentano no inconsciente freudiano, mesmo reconhecendo a taxativa negação de fenômenos psíquicos inconscientes por parte do filósofo (Cohen, 2000); (d) a ausência de qualquer menção a Brentano em um texto que se propõe a tratar das influências filosóficas sobre o conceito de representação (Rizzuto, 1993); e (e) a defesa de contornos aristotélicos e escolásticos como um todo, na obra de Freud, herança dos ensinamentos de Brentano (Beuchot, 1998). Essa relação de autores revela apenas o que entendemos ser o ponto mais característico da contribuição de cada um. Não devemos concluir a exclusão automática de outros pontos. Todos os autores que assumem a presença de uma influência brentaniana na obra de Freud concordam quanto à noção de representação, por exemplo. Aviva Cohen (2000) destaca-se pela inclusão do inconsciente. A pobreza consensual, portanto, denota muito mais um tema pouco explorado do que a liberdade de interpretações.

Uma última medida cautelar se faz necessária: entendemos que tratar da postura de Freud perante a filosofia, de um modo geral, exige um cuidado especial.

Há evidências de sobra para sugerirmos que os ensinamentos filosóficos e psicológicos de Brentano tiveram impacto significativo no desenvolvimento teórico de Freud. [...] Podemos, por exemplo, revisar a ideia comum de que Freud era avesso à filosofia. [...] É evidente que Freud frequentemente critica algo a que ele se refere como 'filosofia'. No entanto, quando assim o faz, ele não está se referindo à disciplina como um todo, mas segue os passos de Brentano na rejeição da metafísica especulativa de Hegel, Schelling e Fichte. Brentano se considerava um cientista natural, trabalhando objetivamente com a experiência enquanto seu guia. Ele insistiu que o verdadeiro método da filosofia não é outro senão o da ciência natural. Para Carl Strumpf, dentre outros, era uma nova e incomparavelmente mais séria e aprofundada forma de se compreender a filosofia. (Cohen, 2002, p. 89)

$\mathrm{O}$ estudo da correspondência entre Freud e Silberstein nos revela que o interesse despertado em Freud por Brentano o levou a cogitar seriamente doutorar-se em Filosofia (p. 116, em carta de março de 1875). No mesmo período, o jovem estudante confessava-se, em virtude dos ensinamentos do mestre, um teimoso e relutante ex-materialista. São recorrentes nas cartas de Freud menções às sucessivas provas da existência de Deus oferecidas por Brentano. "Ele me comprova a existência de Deus com tão pouca parcialidade e com tanta exatidão como qualquer outro faria com a vantagem da teoria da ondulação em relação à da emissão" (p. 123). Lindenfeld (1980) e o próprio Freud, em carta de setembro de 1875 (p. 150), nos revelam o maldoso burburinho onipresente dentre os colegas do mestre: "Tratase de um jesuíta disfarçado!" Longe de considerarmos o epíteto ofensivo, nem por isso deixava de ser uma inverdade
- Brentano já havia abandonado o sacerdócio há alguns anos (Lindenfeld, 1980). Ocorre que este pode vir a ser o preço a se pagar em decorrência de incursões no terreno da metafísica. E o que já se constituía injusto para com Brentano, mais ainda o seria com relação a Freud: a articulação proposta neste trabalho em momento algum visa atribuir a Freud quaisquer contornos de um metafísico tradicionalista das sombras ou algo que o valha.

\section{Franz Brentano e a Proposta de uma Psicologia Soberana}

Influências indiretas do filósofo à parte, há um ponto de crucial relevância, em franca dívida para com os desdobramentos permitidos pela noção de concomitância dependente, capaz de situar Brentano antes mesmo de Jackson na hierarquia dos inspiradores de Freud. Os esforços para a edificação de uma disciplina soberana, "com sua própria linguagem, conceitos e construções, que não eram físico-químicos, tampouco neurofisiológicos" (Edelheit, 1976 , p. 24) não precisam ser inferidos ou compreendidos sob a forma de consequência dos ensinamentos de Brentano: trata-se de sua intenção declarada, publicada já na primeira edição de sua mais famosa obra: Psicologia do ponto de vista empírico (Brentano, 1874/1995). Vale lembrar que o livro de Brentano foi lançado em 1874, no mesmo ano em que Freud o conheceu.

Brentano é rigorosamente metódico na escrita. Ele inicia sua empreitada (1874/1995) organizando hierarquicamente a argumentação. Afirma ser de importância "primária e universal" (p. 33) a investigação dos elementos mentais mais simples, base necessária sobre a qual outros tantos fenômenos mais complexos se ergueriam posteriormente. Tais elementos-base o autor encontrará nas sensações, justificando seu posicionamento no fato de serem as sensações inquestionavelmente o ponto de partida para diversos outros fenômenos mentais, ao ponto mesmo de alguns cientistas, de acordo com ele, tentarem remeter a totalidade dos fenômenos mentais às suas raízes sensoriais. Não devemos, em nossa leitura, concluir desta remissão ao sensorial uma decorrente (ou mesmo implícita) redução ao sensorial. Tratando-se as sensações do efeito de uma estimulação física, conclui-se acerca da origem destes elementos-base um processo de natureza psico-física. Abrem-se, dessa maneira, os portões para a entrada da fisiologia na discussão, e é certo afirmar que Brentano em momento algum irá negligenciar, tampouco subestimar a importância dos processos fisiológicos para a psicologia de um modo geral. Em um tópico no qual discorre sobre as leis de sucessão dos fenômenos mentais, ele afirma categoricamente a "completa dependência" (p. 35) dos fenômenos mentais quanto a uma "variedade de condições fisiológicas sobre as quais nosso conhecimento ainda é muito incompleto" (p. 35). O filósofo entende estar diante de leis empíricas cuja explicação requereria "uma análise exata dos estados fisiológicos com os quais [os fenômenos mentais] estariam conectados" (p. 35).

Tamanha é a ênfase conferida ao domínio fisiológico, que Brentano parece ter julgado necessário prolongar-se com a seguinte elucidação, encontrada imediatamente após 
os referidos apontamentos. Trata-se de uma passagem cujo valor nos é sem dúvida imenso:

O que eu digo não deve ser compreendido como se eu acreditasse que se deve deduzir as leis fundamentais governantes da sucessão dos fenômenos mentais a partir das leis fisiológicas, e talvez ir ainda mais longe e derivar estas últimas das leis governantes dos fenômenos químicos e físicos no sentido mais estreito. Isso seria tolice. [...] O que me parece desejável e necessário para maiores explicações acerca das leis mentais não é a sua dedução a partir das leis físicas. Em casos simples, a explicação que tenho em mente envolveria meramente a enumeração das pré-condições ou concomitantes fisiológicos aproximados e imediatos com o máximo de precisão. [...] As leis que constituem as nossas mais elevadas leis no presente momento iriam, no entanto, reaparecer de maneira um tanto quanto alterada, como leis derivadas. $\mathrm{E}$ a maior parte, senão mesmo toda a psicologia, tomaria um aspecto metadefisiológico, metade-psicológico. (Brentano, 1874/1995, pp. 35-36, o grifo é nosso)

O que se segue em sua investigação rumo aos meios "puramente psicológicos [...] não suficientemente utilizados" (p. 35) é uma sistemática refutação direcionada às tentativas de redução da psicologia à fisiologia. O filósofo inicia sua exposição criticando pensadores como Horwicz (18311894) e Comte (1798-1857), acusando-os de superestimar os serviços passíveis de serem prestados à psicologia pela fisiologia. Tomando por base a relação entre ambos os domínios (a fisiologia lidaria com o "conceito imediatamente superior" (p. 37) ao da psicologia, a saber, a vida), a fisiologia estaria para a psicologia assim como a matemática está para a física, ou a astronomia para a geografia. Porém, contra-argumenta Brentano, ainda que lidemos nestes casos com relações de inquestionável utilidade e mesmo indispensabilidade, "qualquer um pode constatar que o físico não obteria quaisquer progressos em sua pesquisa caso se utilizasse de meios exclusivamente matemáticos" (p. 37) na condução das mesmas. A matemática, exemplifica o filósofo, nada pode dizer sobre o número de classes fundamentais de fenômenos com os quais lida a física.

Brentano prossegue, prevendo uma possível objeção às analogias supracitadas. Poder-se-ia afirmar que a relação entre fisiologia e psicologia, ao contrário da relação entre matemática e física, por exemplo, apresenta uma "conexão particularmente íntima" (p. 37), posto que os fenômenos estudados pela fisiologia seriam a condição mesma para a ocorrência dos fenômenos psicológicos. Neste ponto, o neoescolástico direciona sua contra argumentação às interações existentes entre os domínios da química e física inorgânica e as fronteiras da própria fisiologia:

O domínio inorgânico contém as condições de organismos cuja existência depende de uma interação constante e íntima com este. Contudo, apesar do auxílio capaz de ser oferecido ao fisiologista pela física ou química inorgânica, seria ele capaz de obter delas informações adequadas sobre a estrutura dos organismos? Ele não se veria forçado a, ao contrário, derivar tanto a totalidade da estrutura, tal como as funções das partes individuais, a partir dos próprios fenômenos fisiológicos? (Brentano, 1874/1995, pp. 37-38)

Novamente, Brentano adianta-se quanto às possíveis críticas a esse último posicionamento: sim, a relação constante e mútua, nos diz o filósofo, referente aos domínios orgânico e inorgânico, é inquestionável. Não obstante, seria ainda possível afirmar, acerca desta analogia, a seguinte insuficiência: ao contrário do que se observa na interação entre a fisiologia e a psicologia, os fenômenos inorgânicos não constituiriam o "substrato material" (p. 38) dos fenômenos orgânicos. Brentano conclui:

A única coisa que é imediatamente óbvia é que a relação entre fenômenos mentais e seus concomitantes fenômenos fisiológicos é de fato muito diferente da relação existente entre os fenômenos inorgânicos com os quais lida o químico e os organismos tratados pelo fisiologista. (Brentano, 1874/1995, p. 38, o grifo é nosso)

É importante ressaltarmos que o posicionamento de Brentano visto até aqui diz respeito sobretudo ao que o filósofo entende como sendo ideal quanto à metodologia de investigação psicológica. É a partir desse contexto que ele ergue sua crítica direcionada à redução do domínio psicológico ao fisiológico. Os ensinamentos de Brentano, mesmo quando restritos ou ao menos provenientes de um contexto de discussão metodológica, já apresentam uma afinidade tal com a noção freudiana de concomitância dependente, conforme teremos a chance de ver, capaz de provocar certa incredulidade ao constatarmos a atenção conferida à articulação aqui proposta. Mas a contribuição de Brentano está longe de limitar-se aos domínios do método. Eis que, partindo deste domínio, chegamos ao ponto onde o reducionismo em questão repousa na ideia que confere ao fisiológico o estatuto de substrato material do psicológico, para aproveitarmos o termo utilizado por Brentano. É chegado o momento, portanto, de avançarmos rumo à contribuição brentaniana de caráter ontológico.

\section{O Hilemorfismo e a Cosmologia Antiga}

Pode-se notar que com o reflorescimento da filosofia aristotélica durante o período escolástico, o termo grego morphe veio naturalmente a ser substituído pelo latim forma, e hyle traduziuse por materia. E por uma certa evolução, ademais, a materia escolástica transformou-se na matéria da física newtoniana - seu sentido exato, no entanto, está longe de ser claro. Ontologicamente falando, este remanescente da era newtoniana constitui, em todo caso, um híbrido confuso de materia e forma no sentido autêntico. (Smith, 2005, p. 85)

Iniciemos pelo conceito de matéria, tão caro à compreensão de uma concepção da realidade. Ferrater-Mora (2000) afirma ter sido com Aristóteles que, pela primeira vez no pensamento ocidental, foi conferido à matéria um caráter filosófico e propriamente técnico. A contribuição de seus antecessores - Platão e os pré-socráticos - não é negligenciada, mas é por meio de sua obra que não apenas o conceito será bem definido como consideravelmente enriquecido. A matéria, para Aristóteles, é obrigatoriamente caracterizada por sua receptividade, "não sendo propriamente matéria caso não esteja 'disposta' a receber alguma determinação" (FerraterMora, 2000, p. 1892).

Ferrater-Mora (2000) esclarece, ainda, não ser fácil nem legítimo distinguir no estagirita o que precisamente corresponde à sua Física e sua Metafísica, mas supõe, 
“com vistas a uma maior clareza, que essa distinção é muito mais nítida do que aparece nos próprios textos do filósofo" (Ferrater-Mora, 2000, p. 1893). Na Física, matéria é compreendida por vezes como substrato, a saber: aquilo que está sujeito a mudanças e donde se inferem as qualidades. "Parece, pois, que a matéria é a substância" (Ferrater-Mora, 2000, p. 1893), conclui o autor, para logo em seguida afirmar ser esta uma conclusão falsa, na medida em que a matéria no sentido aristotélico não é propriamente a substância enquanto tal, mas aquilo que é comum a todas as substâncias, aquilo de que elas são feitas. De fato, dizer que uma coisa é feita de si mesma não faz o menor sentido. Para Aristóteles, a matéria é, portanto, a matriz da realidade física e não a própria realidade física.

As considerações metafísicas que dizem respeito à matéria são sensivelmente análogas às físicas, sendo que reside aqui a ênfase ao conceito de forma supracitado. Posto de outra maneira, o estudo aristotélico da matéria quase sempre assume um caráter metafísico, sendo a matéria compreendida como parte do famoso binômio matéria-forma. A matéria seria, assim, aquilo com o qual se faz algo, sendo que este ato de fazer pode ter tanto o sentido de um processo natural como o de uma produção humana. Conclui-se que a concepção aristotélica de matéria assume necessariamente um caráter relativo. Matéria é sempre relativa à forma, de modo que o tecido do real revela-se forçosamente sob o par matéria-forma. Daí a afirmação de que a realidade não é em última análise material - tampouco formal - mas sempre um composto de ambos.

O ponto é que a forma de uma entidade existente é precisamente o seu aspecto cognoscível. Resumidamente, pode-se dizer que uma coisa é inteligível em virtude de sua forma - porém existente por conta da matéria. Eu não digo aqui 'da sua matéria', sobretudo porque matéria, estritamente falando, não pertence à coisa - da mesma forma que do oceano não dizemos pertencer a uma onda em particular. Forma, por outro lado, pertence à coisa: pois a forma de uma entidade é a sua essência verdadeira. É aquilo que nós sabemos e podemos saber, é o 'quê' ou qüididade da coisa. Deve-se ter em mente, no entanto, que a entidade existente não coincide simplesmente com a sua qüididade: possui também um aspecto material, o qual permanece ininteligível - um fato da maior importância, certamente. (Smith, 2005, p. 85)

O que nos interessa é deixar bem claro que Brentano segue fielmente os passos de seus mestres, erguendo a sua própria teoria sobre o arcabouço milenar da filosofia ocidental. A matéria não é, em hipótese alguma para o neoescolástico, algo que se baste a si mesma. Pois é precisamente a partir deste ponto que se torna clara a ruptura moderna, e da tentativa de contorná-la por meio de um resgate conceitual, resulta em grande parte o mérito de Brentano - não limitado ao trajeto de Freud, naturalmente. Ferrater-Mora (2000) revela que, se por um lado não podemos afirmar que esta concepção antiga de matéria foi completamente posta de lado com o surgimento da Modernidade, "é característico da Idade Moderna o fato de ter-se ocupado principalmente da noção de matéria enquanto constitutiva da realidade 'material' ou 'natural"' (p. 1896). Eis a concepção científico-natural da matéria. Ainda que em um primeiro momento fosse possível identificar alguma semelhança, por peculiar que fosse, com o conceito relativo, tal como encontrado na doutrina hilemórfica, "cada vez mais se tendeu a estudar a matéria como realidade una e única" (p. 1896).

A ciência moderna teve início enquanto um amálgama da metafísica cartesiana com o empirismo baconiano, tendo sido a incongruência de ambos percebida de imediato por alguns importantes filósofos. No fim das contas, a união resultante não oferece uma verdadeira síntese, e o que é de fato levado em consideração não é a ontologia cartesiana, tampouco sua epistemologia, mas precisamente o método baconiano. [...] É certo afirmar que a concepção cartesiana de res extensa (matéria pura) teve um papel fundamental na motivação e orientação da investigação científica. [...] Este reducionismo metodológico, no entanto, não pressupõe ou herda uma ontologia. Pode-se dizer ser metafisicamente neutro. Entretanto, se por um lado a ciência não autoriza de jure um reducionismo de tipo ontológico, ela assim o faz de facto. A tendência a negar aquilo que a ciência não é capaz de alcançar prova-se irresistível. É fato que a ciência gera cientificismo e a bifurcação é sem dúvida o dogma científico básico. Como Gilbert Durand sabiamente observou: O dualismo é a grande estrutura esquizomórfica da inteligência ocidental. (Smith, 2004, p. 229)

A constatação da dita "neutralidade metafísica" intrínseca ao empirismo é essencial para que possamos compreender a obra - e por que não dizer, inclusive, de certo modo a pessoa - de Franz Brentano. Primeiras impressões à parte, não há, rigorosamente falando, incoerência alguma em apropriarse simultaneamente de empirismo e metafísica. Fosse ainda o professor de Freud o padre dos dias de juventude, simplesmente não haveria motivo algum para disfarçar-se. O lugar de destaque conferido pelo filósofo ao empirismo é bem conhecido, a julgar pelo título escolhido para a mais famosa de suas obras, Psicologia do ponto de vista empírico (Brentano, 1874/1995). Já tivemos também a chance de constatar que a ênfase conferida por ele à fisiologia, no âmbito anímico, não implica na redução filosoficamente ingênua do segundo ao primeiro. Mais ainda: Brentano dá ao seu leitor todos os indícios de que está perfeitamente ciente da irresistível tendência nesse sentido. $\mathrm{O}$ antídoto oferecido pelo mestre pode facilmente ser inferido a partir de suas instruções a Freud: leia tudo de Descartes, mas não caia na armadilha do dualismo de substância. Encontramos uma bela exemplificação da apropriação do hilemorfismo por parte de Brentano no artigo A epistemologia de Brentano, de Linda McAlister (2004), tradutora de sua Psicologia do ponto de vista empírico:

Brentano reitera a sua afinidade com Aristóteles neste ponto [...] em uma tentativa de elucidar melhor a sua posição. A referência a Aristóteles ajuda a explicar como o objeto de um pensamento, por exemplo, poderia ao mesmo tempo ser alguma coisa que, caso de fato exista, seja externo à mente, e ainda assim esteja relacionado com a mente que o pensa. Ele aponta que, para Aristóteles, na percepção sensorial a forma do objeto é recebida pelos sentidos na ausência da matéria, e, da mesma maneira, o intelecto recebe a forma inteligível abstraída da matéria. Brentano ressalta: não era a idéia dele (Aristóteles) essencialmente a mesma que a nossa? (McAlister, 2004, p. 153, o grifo é nosso)

Em palestra proferida no ano de 1986, o filósofo americano David L. Schindler tratou do grande atrito 
- intrínseco e profundo - presente na articulação das concepções acerca da Natureza, referentes ao que ele chama de visão grega clássica e visão moderna clássica, respectivamente recorrendo a Aristóteles e Descartes e suas influências sobre o pensamento ocidental. Schindler inicia sua exposição com uma afirmação que já nos é familiar: diz que, na visão grega clássica, a natureza é matéria apenas em certo sentido. "Ademais, natureza significa o princípio material originário do qual é feito ou do qual deriva algum objeto natural, e que é privado de forma e incapaz de mudar em virtude unicamente da potência que lhe é própria." (Aristóteles, 2005, p. 199). Em um segundo sentido, ela não é matéria, uma vez que a Natureza no sentido próprio e total seria algo atual (ato), sendo a matéria em seu sentido básico não algo atual, mas aquilo que tem a capacidade de tornar-se atual (potência). Logo, a Natureza em seu sentido próprio deve ser não a matéria, mas aquilo - $\mathrm{o}$ ato ou atividade - em virtude do que a natureza, e, portanto, a matéria, são atuais.

Reconhecendo a tremenda complexidade do assunto, o palestrante conclui ser a matéria um conceito relativo conforme já tratamos anteriormente - e que, portanto, só pode ser entendido devidamente em sua atualidade no que se refere à Natureza em seu sentido completo e apropriado. A Natureza - aquilo em relação ao que a matéria toma seu sentido total - é, assim, caracterizada por ato ou atividade que é imanente, formal, final, unificador e completo ou total. Esta concepção da Natureza é chamada orgânica, por ser característica dos organismos.

Em contrapartida, defende Schindler (1986), a matéria relativa presente na doutrina hilemórfica surge no pensamento moderno enquanto conceito absoluto. A matéria que, em qualquer de suas instâncias atuais, era entendida apenas em relação a uma Natureza cujo ato primário é formal e final, torna-se a partir de Descartes precisamente idêntica a uma natureza da qual a mente - identificada aqui com a atividade formal e final - já não faz mais parte. A concepção cartesiana de matéria é claramente distinta da sua ideia de mente. "Descartes equiparou matéria à extensão, de acordo com sua característica redução, ou tentativa de redução, da realidade material às propriedades geométricas do espaço" (Ferrater-Mora, 2000, p. 1896). O sentido de Natureza passa, então, a ser absorvido por uma matéria compreendida como aquilo de que tudo, à exceção da extensão, é em princípio removido. Feitas essas considerações, retornemos à noção de concomitância, tendo em vista o que aqui foi exposto.

\section{Do Hilemorfismo à Concomitância Dependente}

Se há um ponto sobre o qual podemos afirmar haver ampla concordância entre Sigmund Freud, Franz Brentano e John Hughlings Jackson, trata-se da recusa na classificação de fenômenos psicológicos enquanto não mais que meros epifenômenos de fenômenos físicos - a mente enquanto fumaça emanada pela fábrica cerebral, por assim dizer. Restanos agora abordar a doutrina da concomitância dependente, tomando por base o pensamento destes três autores. Do resultado da articulação proposta, lançaremos luz sobre a importância da consideração dos ensinamentos de Brentano sobre este ponto específico da obra de Freud.
Primeiramente, uma vez que defendemos a influência indireta de Brentano sobre uma concepção freudiana cuja origem o próprio autor remete a Hughlings Jackson, cabenos expor as distinções entre as concomitâncias freudiana e jacksoniana. Brechas, poderíamos dizer, capazes de justificar a busca pelo auxílio do filósofo. A pesquisa bibliográfica nos revela que em seu manuscrito sobre as afasias (Freud, 1891/1977), o autor recorre à obra de Jackson publicada em 1878: On affections of speech from disease of the brain. Nesta obra, Jackson condena a "falácia" (p. 156) de que estados físicos possam transformar-se em estados psíquicos e vice-versa: vibrações nervosas jamais se tornariam sensações, tal como uma idéia seria incapaz de produzir um movimento. Uma exposição mais completa de sua doutrina da concomitância, no entanto, encontramos em palestra proferida no ano de 1884 :

Agora falo da relação da consciência com os estados nervosos.

A doutrina que sustento é: primeiro, que estados de consciência (ou, sinonimamente, estados mentais) são completamente diferentes de estados nervosos; segundo, que as duas coisas ocorrem juntas - que para cada estado mental há um estado nervoso correlativo; terceiro, que, embora as duas coisas ocorram em um paralelismo, não há interferência de uma sobre a outra. Isso pode ser chamado de doutrina de concomitância. [...] A imagem visual, um puro estado mental, aparece em paralelo com - surge durante (não a partir de) - as atividades das duas conexões mais altas dessa cadeia puramente física. Por assim dizer, ela "aparece fora" dessas conexões. (Jackson, 1884/2013, p. 240, o grifo é do autor)

Voltemos nosso olhar à concomitância de Freud. Ao contrário de Jackson, que afirma taxativamente a completa diferença entre estados nervosos e estados mentais, não havendo interferência entre eles apesar de suas ocorrências forçosamente paralelas, Freud assume uma postura mais cautelosa. Em 1891, por exemplo, o metapsicólogo inicia a exposição do seu entendimento da doutrina de concomitância dizendo que "provavelmente" (p. 31) os processos fisiológicos não se encontrariam em relação de causalidade com os processos psíquicos. Um ano antes, no texto de "Tratamento Psíquico", seu entendimento acerca da relação entre o corpo e o psiquismo foi exposto da seguinte forma:

A medicina moderna teve ocasião suficiente de estudar os nexos entre o corporal e o anímico, nexos cuja existência é inegável; mas, em nenhum caso, deixou de apresentar o anímico como comandado pelo corporal e dependente dele. [...] A relação entre o corporal e anímico (no animal, tanto como no homem), é de ação recíproca. (Freud, 1890/1996, p. 116)

Não nos cabe, tal como já afirmamos sobre Freud, inferir acerca das motivações, da instrução e do posicionamento filosófico de Hughlings Jackson. Mas certamente parece difícil conceber algo da ordem de uma interdependência e ação recíproca operando sobre coisas completamente diferentes e, sobretudo, incapazes de exercer influência uma sobre a outra, como defende claramente o britânico. A doutrina da concomitância de Jackson parece limitar-se ao imperativo metodológico: não é desejável que, numa investigação médica, utilize-se expressões parcialmente anatômicas e fisiológicas e parcialmente psicológicas (Jackson, 1878). Eis que ainda paira um desconforto no ar. Ora, a expressão concomitância dependente parece ser 
suficientemente clara em apontar, ou ao menos insinuar um vínculo, um elo estruturalmente indissociável, algo para muito além da analogia encontrada na imagem de dois relógios operando em perfeita harmonia, comumente utilizada para ilustrar a simultaneidade desprovida de causas, defendida pela noção de paralelismo psicofísico. Não afirmamos de forma alguma que Jackson negligenciasse a existência de uma relação entre o anímico e o corporal, naturalmente. Mas não é curioso que o inglês tenha nos brindado com um conceito que claramente chama a atenção para algo que, na melhor das hipóteses, não parece figurar nos seus interesses? A solução do enigma nos conduz ao terreno das obviedades desapercebidas: John Hughlings Jackson jamais falou em concomitância dependente.

Há ainda um ponto de grande relevância a ser esclarecido. Mesmo a tradução para o português das Afasias de Freud (1891/1977) mantém-se fiel a um detalhe encontrado no texto original em alemão: a expressão dependent concomitant aparece em inglês. Isso, aliado aos elogios que surgem logo em seguida em uma nota de rodapé, direcionados ao colega britânico responsável pelo que ele próprio chamou de doutrina de concomitância, parece sugerir tratar-se o dependent concomitant de uma citação ipsis litteris de um termo cunhado por Jackson. Nossa pesquisa aponta em outra direção. Tenha sido por um mero descuido ou apenas uma forma simpática de render-lhe homenagem, tudo leva a crer que a dependência a figurar na concomitância remete-nos a uma iniciativa do próprio Freud.

Freud e Bain assumiram um posicionamento quanto à relação entre mente e cérebro que era similar, ainda que não idêntico, ao paralelismo psicofísico adotado por Hughlings Jackson e Ferrier. A diferença era que, para Freud e Bain, os processos mentais eram dependentes concomitantes do fisiológico e não apenas concomitantes, como era o caso com Jackson e Ferrier. (Macmillan, 2002, p. 270, o grifo é nosso)

Rigorosamente falando, portanto, a doutrina do paralelismo psicofísico não é suficiente para dar conta da amplitude intrínseca à noção de concomitância tal como defendida por Sigmund Freud, apesar de o ser quando tratamos da abordagem proposta por seu colega inglês. Não negamos, obviamente, o patente parentesco encontrado entre ambas as concepções, tampouco é nosso interesse diminuir ou mesmo negar a importantíssima contribuição de Jackson. Freud apenas deu um passo além. Passo este que nos direciona, finalmente, de volta à trilha aberta por Brentano até a Grécia Antiga de Aristóteles.

Freud supunha duas cadeias, a material e a psíquica, ligadas, inter-relacionadas, em conexão, mas simultaneamente distintas. [...] a distinção entre as duas cadeias, aliada à afirmação de que a conexão entre elas não seguiria uma causalidade mecânica, sugere que Freud as compreendia de maneira paralelista. Fica evidente que, se por um lado, ele não concebia as cadeias como substâncias distintas, operando de modo independente, por outro lado, também não reduzia uma à outra. (Winograd, 2013, p. 44)

As cadeias material e psíquica, irredutíveis uma a outra, no entanto indistintas do ponto de vista substancial. Eis a afirmação em consonância perfeita para com a doutrina hilemórfica. Eis o possível fruto dos ensinamentos de Brentano, revelado pelos desdobramentos promovidos por uma única palavra, uma simples palavra que faz toda a diferença: dependente.

Antes de prosseguirmos às articulações tão flagrantemente possíveis entre as doutrinas da concomitância dependente freudiana e do hilemorfismo, julgamos necessários alguns apontamentos finais capazes de firmar, para além de qualquer dúvida, o papel que Brentano teria tido na apresentação destes conceitos ao jovem Freud. Já sabemos que o contato entre professor e aluno não foi corriqueiro, tampouco superficial. Sabemos ainda que a obra de Aristóteles foi tema de algumas de suas aulas. Quanto à anteriormente citada fidelidade de Brentano para com o estagirita e S. Tomás de Aquino, a consulta à Psychology from an empirical standpoint (Brentano, 1874/1995) já seria suficiente, mas há ainda a excelente obra Aristotle and his worldview (Brentano, 1978) capaz de sanar quaisquer dúvidas remanescentes. Poder-seia objetar: mas e quanto ao hilemorfismo especificamente? Que garantias temos de que Freud teria entrado em contato com a doutrina? Ora, o próprio Freud nos fornece os relatos das inúmeras provas da existência de Deus oferecidas pelo mestre. É duvidoso, para dizer o mínimo, que Brentano argumentasse sobre este assunto, especificamente, baseandose exclusivamente no empirismo britânico, sua outra grande fonte de inspiração. O contato com a metafísica é certo; e tratar de metafísica aristotélico-tomista desconhecendo o hilemorfismo é tão concebível quanto discorrer sobre metapsicologia freudiana ignorando por completo o conceito de representação, por exemplo. Temos ainda evidências de que Brentano entendia o processo de percepção da mesma maneira que seus mestres: a forma seria captada pelos sentidos na ausência da matéria (McAlister, 2004). Finalmente, o breve capítulo intitulado "Interação entre mente e corpo" (Brentano, 1978, p. 110) claramente aponta para algo da ordem de uma ação recíproca.

É característico da doutrina hilemórfica o chamado dualismo de propriedade. Essa modalidade de dualismo distingue-se, pode-se dizer, do dualismo de substância, este encontrando nas noções cartesianas de res cogitans e res extensa as suas mais conhecidas exemplificações. Poderíamos dizer, acerca do binômio matéria-forma, ser compatível com a noção freudiana de concomitância na sua recusa de uma causalidade mecânica entre as cadeias material e psíquica. Isto estaria correto, porém o paralelismo psicofísico tal como defendido por Jackson já se posiciona da mesma forma sobre este ponto. Nesse caso, portanto, a complementaridade por nós apontada no início do artigo, presente entre as heranças de Jackson e Brentano, seria inócua. Poderíamos também articular a indistinção substancial entre as cadeias, defendida por Freud, com o fato de consistir o hilemorfismo - e toda a cosmologia nele respaldada - em uma doutrina francamente oposta a qualquer dualismo de cunho cartesiano. Neste ponto, a argumentação começaria a ficar mais interessante, dando conta da complementaridade quanto à herança de Jackson. O paralelismo psicofísico do neurologista inglês não se aprofunda sobre este ponto especificamente. Na verdade, ao afirmar a completa diferença e ausência de interferência entre os estados nervosos e os estados mentais, permite uma interpretação compatível com alguma modalidade de dualismo de substância. Não defendemos que essa fosse a intenção de Jackson, apenas que a forma como o assunto 
é tratado por ele permite esta leitura. Ainda nos restaria, contudo, demonstrar como a articulação entre o hilemorfismo e a noção de concomitância dependente seria capaz de elevar a concepção freudiana seguramente além dos limites de um imperativo metodológico.

Devemos ressaltar que, diferentemente da noção freudiana de concomitância dependente, os desdobramentos permitidos pela utilização do binômio forma-matéria não encontram na relação corpo-psiquismo a fronteira de suas pretensões. Conforme já tivemos a chance de conferir, a doutrina em questão projeta-se sobre todos os entes corpóreos existentes, sendo portanto aplicável à estrutura da realidade como um todo, nos abarcando e transcendendo: nós, nossos corpos e nossas mentes, por assim dizer. Isso é fundamental para que possamos dar o próximo passo. Sabemos ainda que Freud, Brentano e Jackson posicionam-se contrariamente à redução do anímico ao corpóreo. Ora, questionemo-nos: qual a premissa necessária para que se possa sequer conceber tal redução? A resposta é simples: a redução do anímico ao corpóreo pressupõe, necessariamente, a noção de um corpo substancialmente autossuficiente. Em última análise, a possibilidade de redução requer um conceito de matéria capaz de bastar-se a si mesma, conceito este que, conforme já vimos, é completamente inadmissível dentro de uma perspectiva hilemórfica.

\section{Considerações Finais}

Os ensinamentos de Brentano, portanto, não vêm simplesmente corroborar com a noção de concomitância dependente desenvolvida por Freud. Muito além disso, na verdade, uma vez aceitos na qualidade de arcabouço conceitual, simplesmente não restaria a possibilidade de ser de outra maneira. Qualquer tentativa de elucidar a natureza da interação entre corpo e psiquismo deve, primeiramente, se propor a rever as suas raízes epistemológicas mais profundas, enraizadas, e muitas vezes precisamente por isso fadadas à condição de ponto de partida incontornável.

Não pode haver uma ontologia viável que não invoque, de um jeito ou de outro, o paradigma hilemórfico. A ideia mesma de existência corpórea, pode-se dizer, demanda dois princípios complementares, que por sua vez não podem senão responder às concepções gêmeas de 'matéria' e 'forma'. E isto explica por que noções correspondentes são encontradas nas grandes ontologias, da China e Índia até a Grécia e antiga Palestina. É certo afirmar que isto é muito mais evidente nos casos da China, Índia e Grécia do que na antiga Palestina. Ainda assim, não se pode negar que a concepção hilemórfica seja, da mesma forma, Bíblica. Mestre Eckhart, para citar um, informou-nos do seguinte fato: "É necessário que se saiba, em primeiro lugar, que 'matéria' e 'forma' não são dois tipos de entidades existentes, mas dois princípios dos seres criados. Este é o significado das palavras 'No princípio Deus criou o céu e a terra', a saber, 'forma' e 'matéria', dois princípios das coisas. (Smith, 2005, p. 76, o grifo é nosso)

A menção a Mestre Eckhart visa eliminar qualquer possibilidade de mal-entendido referente a deturpações do sentido verdadeiro do binômio, decorrentes sobretudo de possíveis resquícios de cartesianismo a permear o nosso próprio olhar sobre a realidade. Não se tratam, aqui, de dois tipos de entidades - ou substâncias distintas -, mas de princípios dos seres criados. Permanecemos na esfera da entidade unitária. Mais ainda: ao respaldar sua afirmação acerca do hilemorfismo no fato de este ter surgido de um modo ou de outro em variadas culturas ao longo dos tempos, Smith (2005) a reforça muito bem. Ou aceitamos que ao menos a proposta é digna de atenção cuidadosa, ou condenamos a vasta comunidade dos mortos à estupidez endêmica - o que é, no mínimo, muito improvável.

Não é necessário nenhum grande esforço imaginativo no sentido de nos facilitar a assimilação da consonância encontrada entre as doutrinas da concomitância freudiana e do hilemorfismo aristotélico-tomista endossado por Brentano. Ao identificar, por meio da noção de concomitância dependente, que a "estrutura interna [dos processos psicológicos] independe das estruturas anatômica e fisiológica, e deve ser abordada em seus próprios termos" (Winograd, 2013, p. 50), o respaldo em uma cosmologia antiga, que encontre no hilemorfismo (ou em algum outro ponto de vista que lhe seja análogo) um de seus alicerces, é tremendamente elucidativo. A mente não é o cérebro, tampouco é causada por ele. A mente é por meio do cérebro. De fato, não se trata, como defendido pela mesma autora, de ultrapassar as barreiras do Cartesianismo. A perspectiva aqui proposta nos aponta o dualismo de propriedade não como uma solução para os impasses do dualismo de substância de René Descartes - isso sequer seria possível, se considerarmos o primeiro enquanto historicamente anterior ao segundo. Longe disso, ela afirma acerca dele não passar de um falso problema, e justamente por isso, não há, a rigor, solução alguma a ser encontrada. Para que ultrapassássemos o dualismo cartesiano, teríamos que primeiro aceitá-lo enquanto premissa. Mas um filósofo como Brentano, ou mesmo Aristóteles, apenas responderia: Ora, mas as coisas simplesmente não são assim.

\section{Referências}

Aristóteles (2002). Metafísica. São Paulo: Edições Loyola.

Barclay, J. R. (1964). Franz Brentano and Sigmund Freud. Journal of Existentialism, 5, 1-36

Beuchot, M. (1998). Aristóteles y la escolástica en Freud a través de Brentano. Espíritu, 47(118), 161-168

Brentano, F. (1995). Psychology from an empirical standpoint. London: Routledge. (Original publicado em 1874)

Boehlich, W. (Ed.). (1995). As Cartas de Sigmund Freud para Eduard Silberstein 1871-1881. Rio de Janeiro: Imago

Brentano, F. (1978). Aristotle and his worldview. Los Angeles: University of California Press. (Original publicado em 1911)

Cataldo-Maria, T. M. S., \& Winograd, M. (2013). Freud e Brentano: Mais que um flerte filosófico. Psico, 44(1), 34-44.

Cohen, A. (2000). The origins of Freud's theory of the unconscious: A philosophical link. Psychoanalytische Perspectieven, 41/42, 109-122.

Cohen, A. (2002). Franz Brentano: Freud's philosophical mentor. In G. Van De Vijver \& F. Vivjer (Ed), The pre-psychoanalytic writings of Sigmund Freud, (pp.88-100). London: Karnac Books. 
Edelheit, H. (1976). Complementarity as a rule in psychological research: Jackson, Freud and the mind / body problem. The International Journal of Psychoanalysis, 57(23), 23-29.

Eiling, P. (1994). Reader in the history of aphasia: From Franz Gall to Norman Geschwind. Philadelphia: John Benjamins Publishing Comapany.

Ferrater-Mora, J. (2000). Dicionário de Filosofia. São Paulo: Edições Loyola.

Freud, S. (1977). A interpretação das afasias. Lisboa: Edições 70. (Original publicado em 1891) Freud, S. (1996). Tratamiento psíquico. Obras Completas, 1, 111-132 Buenos Aires: Amorrortu. (Original publicado em 1890)

Freud, S. (1891/1977). A Interpretação das Afasias. Lisboa: Edições 70

Garcia-Roza, L.A. (2004). Introdução à metapsicologia freudiana, 1. Rio de Janeiro: Jorge Zahar Ed.

Jackson, J.H. (1958). On affections of speech from disease of the brain. Selected writings of John Hughlings Jackson, 2. New York: Basic Books. (Original publicado em 1878)

Jackson, J. H.(1958). Evolução e dissolução do sistema nervoso Palestras croonianas realizadas no Royal College of Physicians. In M. Winograd (Ed.) Freud e a fábrica da alma: Sobre a relação corpo-psiquismo em psicanálise, (pp. 183-248). Curitiba: Appris. (Original publicado em 1884)

Lindenfeld, D. F. (1980). The transformation of positivism: Alexius Meinong and European thought, (pp. 1880-1920). Berkeley: University of California Press.
Macmillan, M. (2002). An odd kind of fame: Stories of Phineas Gage. Massachusetts: M.I.T. Press.

McAlister, L. (2004). Brentano's epistemology. In D. Jacquette (Ed.), The Cambridge companion to Brentano. (pp. 149-167). Cambridge: Cambridge University Press.

Merlan, P. (1949). Brentano and Freud - A sequel. Journal of the History of Ideas, 10, 451.

Molnar, M. (2002). John Stuart Mill translated by Sigmund Freud. In G. Van De Vijver \& F. Geerardyn (Eds.), The prepsychoanalytic writings of Sigmund Freud. (pp. 112-122). London: Karnac Books

Rizzuto, A.M. (1993). Freud's speech apparatus and spontaneous speech. The International Journal of Psychoanalysis, 74, 113-127.

Schindler, D. L. (1986). Beyond Mechanism: The universe in recent physics and catholic thought. Maryland: University Press of America.

Smith, W. (2004). The Wisdom of ancient cosmology: Contemporary science in light of tradition. Virginia: The Foundation for Traditional Studies.

Smith, W. (2005). The quantum enigma: Finding the hidden key. New York: Sophia Perennis.

Solms, M., \& Saling M. (1990). A moment of transition: Two neuroscientific articles by Sigmund Freud. London: Karnac Books.

Winograd, M. (2013). Freud e a fábrica da alma: Sobre a relação corpo-psiquismo em psicanálise. Curitiba: Appris. 